\title{
Linking entrepreneurial orientation to project success in construction projects
}

\author{
Muhammad Sajid $^{a^{*}}$, ShahRukh Zaidi ${ }^{\mathrm{b}}$, Saif UL Haq ${ }^{\mathrm{a}}$, M. Ahsan Chugtai ${ }^{\mathrm{a}}$ and Adeel Ahmed ${ }^{\mathrm{a}}$
}

${ }^{a}$ Bahria University, Pakistan

${ }^{b}$ University of Lahore, Pakistan

\section{H R O N I C L E}

\section{Article history:}

Received: January 1, 2021

Received in revised format:

February 1, 2021

Accepted: February 13, 2021

Available online:

February 13, 2021

Keywords:

Project management

Project success

Entrepreneurial orientation

Innovativeness

Risk-Taking

Proactiveness

Entrepreneurship

Structural equation modeling

\begin{abstract}
A B S T RA C T
Entrepreneurial orientation is found to influence Project success along with the moderation of adaptive organizational culture and people centered management in most of the cases. This study, by addressing the moderation brings clarity to the assessment of the relation of entrepreneurial orientation dimensions on project success and is a contribution to the advancement of knowledge enhancement and improvement in Pakistan. A predominantly quantitative research strategy supported by qualitative inputs employed to obtain empirical data from 256 corporate firms in Punjab Pakistan. The gathered data examined by the structural equation modeling through Partial least square method. The results indicate that innovativeness, risk taking and proactiveness reflect the entrepreneurial orientation components. The findings of this study conclude that three dimensions of entrepreneurial orientation Innovation, Risk-taking and Proactiveness have significant and positive influence on project success. When these three dimensions of entrepreneurial orientation are moderated with adaptive organizational culture and People-Centered Management shows moderate to strong relations between different variables with a few insignificant results.
\end{abstract}

(C) 2021 by the authors; licensee Growing Science, Canada

\section{Introduction}

Miller (Miller, 2011) sums up the attributes of an enterprising firm as development, Risky endeavors, and proactive. In view of this, few explorers show that EO is a mix of the three measurements: ingenuity, proactiveness, and risk-taking. Along these lines, EO includes an ability to improve to restore advertised contributions, face challenges to evaluate new and questionable items, benefits, and be more proactive than contenders toward new commercial center chances. (e.g., Covin and Slevin, 1989, 1990, 1991; Knight, 1997; Miller, 1983; Namen and Slevin, 1993; Wiklund, 1999; Zahra \& Covin, 1995; Zahra, 1993a). Without a doubt, numerous tasks are attempted today in little, new business, where the project group is engaged with all business angles, and there is no qualification between venture achievement and item achievement. With expanded pace and rivalry this pattern will just quicken, and it will end up being the standard in enormous associations also. Without projects, associations would get out of date and immaterial, and incapable to adapt to the present serious business condition. Subsequently, regardless of what the inspiration for the project, the inquiry of the project, the achievement is unequivocally connected to an association's adequacy and to its accomplishment over the long haul. However, incidentally, the reasonable comprehension of task achievement is still in its initial days - project achievement has not been ordinarily connected to serious preferred position and winning in the commercial center; and various individuals still see project achievement in various ways. Project the executives writing has additionally been very isolated on this thought and, as of the hour of composing, there are still no acknowledged systems for evaluating project achievement.

\footnotetext{
* Corresponding author.

E-mail address: msajid.bulc@bahria.edu.pk (M. Sajid) 
This thesis depends on the suggestion that projects are a piece of the key administration in associations: Their advantages are multifaceted, and their objectives must be set ahead of time to all the more likely assistance the association meets its shortand long-haul destinations. The motivation behind our experimentally based examination was to build up a multidimensional structure for the appraisal of project achievement.

\subsection{Problem statement and problem description}

Enterprising Orientation (EO) has been concentrated by various examinations, in any case, the individual effect of the factors that characterize EO with the joined impact of Adaptive organizational culture (AOC) and People-focused Management (PCM) on Projects' Success has not been concentrated beforehand in Pakistan (Wiklund \& Shepherd, 2005). Achievement models contain a constrained arrangement of standards that centers just around project the board exertion (Soares, 2013). Much explores have been estimating the imaginativeness with Risk taking and proactiveness alongside different components to see the effect on project achievement or execution, be that as it may, there has been a hole pervasive in evaluating the project accomplishment through these factors by including the impact of versatile authoritative culture and individuals focused administration. Various examinations have concentrated on the pioneering direction (EO) of firms and the elements that add to the achievement or execution of those organizations (for example Miller 1983, Miller and Friesen 1984, Covin and Slevin 1991, Smart and Conant 1994, Lumpkin and Dess 1996, 2001). This examination expands upon past investigation into the EO-execution relationship of pioneering firms by broadening the EO develop and the EO-execution relationship to business holy messengers. This research is to study the factors that drive project decision-making and execution and to achieve better business results and improved organizational effectiveness. EO is a fundamental component of high performing firms (Acs et al., 2018) and is worried about the disclosure and misuse of beneficial chances (Obschonka et al., 2017). It includes the authoritative procedures, techniques, styles, practices, and dynamic exercises utilized by business visionaries that lead to new sections (Stevenson \& Jarillo 1990, Lumpkin and Dess 1996). New section includes propelling another endeavor either through a beginning up firm, by means of a current firm, or inside a bigger partnership (Begeç \& Arun, 2020). It may very well be cultivated by 'entering new or built-up business sectors with new or existing merchandise or administration (Cho \& Lee, 2018).

\section{Literature review, research hypotheses and conceptual model}

These three measurements make extraordinary commitments to a company's general degree of innovative direction (Miller, 2011; Jirásek \& Bílek, 2018; Kim et al., 2018). Specialists additionally have recognized other potential components of EO including serious forcefulness and independence (Alvarez-Torres et al., 2019). These measurements, be that as it may, have not really been received by different scientists (Zaato et al., 2020). This examination utilizes proactiveness, ingenuity, and hazard taking as proportions of business holy messenger EO (Lim \& Kim, 2019; Onwe et al., 2020). These measurements may change autonomously of one another relying upon explicit hierarchical and ecological settings (Martin \& Javalgi, 2016).

\subsection{Relationship between Innovativeness and Project Success}

Inventiveness involves the associations having to recharge, improve, and look for new chances (Kantur, 2016). Ingenuity portrays a company's capacity or ability to advance (Eggers et al., 2014; Mairesse \& Mohnen, 2002). As indicated by Midgley and Dowling (1978), (Hong et al., 2017), inventiveness could be arranged under the character factors that shape the degree to the amount anybody can acknowledge and receive new thoughts, items, and frameworks. Also, inventiveness is talked about by Rogers et al. (2005): individuals could be creative on the off chance that they are around connected with a procedure of reception and utilizing new items and frameworks contrasted with others of a similar social framework. So as to truly be roused to embrace this framework, clients ought to have a degree level of ingenuity. In the line with this contention, Aldás-Manzano et al. (2009), (Arora \& Kaur, 2018) factually affirmed the job of inventiveness not just as far as quickening the selection of innovation yet in addition in moderating the degree of Risk related with the utilization of this innovation.

\section{$\mathbf{H}_{1}$ : Innovativeness significantly influences Project Success.}

\subsection{Relationship between Risk Taking and Project Success}

Risk-taking is extremely near that of inventiveness, including striking activities that add project into the obscure or the dedication of critical assets to questionable endeavors (Rauch et al., 2009). It contains general Risk, dynamic Risk, money related Risk, and business chance (Freitas et al., 2012). It is generally undisputable in business examination and practices that Risk administration adds to firm execution by a mix of Risk and return (Hiebl et al., 2019). In any case, it is regularly hard to empower the chiefs at the firm level with a solid enterprising direction to seek after high-chance techniques to accomplish the best execution (Anderson et al., 2015). The Risk-taking conduct produces different results, which need further examination to seek after a superior comprehension of the condition under which firm association is chance improving or Risk lessening (Falkner \& Hiebl, 2015). Risk taking alludes to the organizations' readiness to take advantage of lucky breaks under the unsure business condition (Covin \& Wales, 2012; Baule \& Fandel, 2016). The ordinary hypothesis of Risk-taking motivating forces 
contends that the business person involves a daring individual, which infers better execution (Boermans \& Willebrands, 2017). By putting cash in their little firms, the business visionaries hope to pick up advantages of the project choice, which makes an interpretation into a readiness to face challenges related with the speculation (Block et al., 2015). The result is identified with the run of the mill segments of the personal responsibility suspicion, for example, cost, return, and Risk (Boss and Phillips, 2016). Then again, Risk avoidance alludes to firm conduct that relates to maintaining a strategic distance from the Risk and to settle inside the safe place (Bammens et al., 2015).

\section{$\mathbf{H}_{2}$ : Risk-taking significantly influences Project Success.}

\subsection{Relationship between Proactiveness and Project Success}

Proactiveness additionally will stretch out to ensuring their benefits after they have contributed. Business heavenly attendants receive a functioning administration job in their investee firms (Benjamin \& Margulis, 1996; Mason \& Harrison, 1996, 2002a). This causes them to give helpful contributions to aid the advancement of their speculations just as for individual fulfillment reasons. Accordingly, business blessed messenger proactiveness stretches out not exclusively to the sourcing of speculations to upgrade their choosing better performing investee firms, however it likewise reaches out to their hands-on contribution with their projects to improve execution.

\section{H3: Proactiveness significantly influences Project Success.}

2.4 Relationship of Adaptive Organizational Culture with Innovativeness \& Project Success, Risk-taking \& Project Success and Proactiveness \& Project success

The element of OC that is firmly identified with the presentation development of a firm is flexibility (Dinison \& Mashra, 1995). For a firm to make sure about an upper hand through EO's components of risk taking, creativity, and proactiveness, it needs to have an AO Culture establishment that qualities and acknowledges change. In a professional workplace association, individuals are affected by the convictions, qualities, and practices of the corporate pioneers. In the event that the firm's vital direction is towards business association, individuals are relied upon to do hazardous undertakings that are strong and forceful in seeking after circumstances (Covin \& Wales, 2019). Properties and attributes of the authority group are a significant component that frames an AO-Culture (Carmron \& Quin 1999) and their administration impacts corporate culture (Eisend et al., 2016). This shows the significance of building up a groundbreaking OC that along with overseeing individuals as a wellspring of maintainable intensity and stresses the self-governance of a group, decentralization, and participatory dynamic prompts secure upper hand through superior. AOC is connected to the practical development of an organization through PCM that stresses the significance of participatory dynamic (Engert et al., 2016). The job of the administration is to persuade individuals to seek after new chances and to encourage an inner association condition that best adapts to a quickly evolving condition (Mintzberg 1989). AOC has appeared to positively affect HRM exercises, for example, PCM (Le Roux et al., 2016), (Do et al., 2016). Along these lines, an EO JOURNAL OF EAST-WEST BUSINESS 5 firm that seeks after the improvement of an AOC and PCM authority style will accomplish an upper hand bringing about upgraded firm execution.

$\mathbf{H}_{4}$ : Adaptive organizational culture moderates the impact of Innovativeness on Project Success.
$\mathbf{H}_{5}$ : Adaptive organizational culture moderates the impact of Risk-taking on Project Success.
$\mathbf{H}_{6}$ : Adaptive organizational culture moderates the impact of Proactiveness on Project Success.

\subsection{Relationship of People-Centered Management with Innovativeness \& Project Success, Risk-taking \& Project Success} and Proactiveness \& Project success

PCM firms clearly affirm that individuals are generally imperative to the achievement of an association and they show this practically speaking (Saridakis et al., 2017). Different points of view get to PCM. The asset-based view sets that firm intensity originates from one-of-a-kind groups of unmistakable and immaterial resources that are important, uncommon, incompletely imitable, and maintainable (Saridakis et al., 2017). HR, in asset-based hypothesis, are the wellspring of upper hand as there is the heterogeneity, which can't be effectively imitated or subbed by a contender. In this way, representatives are a wellspring of upper hands (Boon et al., 2018). Besides, business visionaries perceive new open doors that empower them to arrange resources for an unsafe speculation. In this manner, the capacities to perceive openings, organize assets, and make heterogeneous yields become an unmistakable area of business (Lima et al., 2015). Heterogeneous assets are the essential state of business enterprise (Helfat \& Peteraf, 2015) and have the accompanying natures:

Causal vagueness, social multifaceted nature, and way reliance. In this manner, from an asset-based perspective, enterprise and human-driven administration depend on heterogeneity, which is the wellspring of seriousness and the advantages of an organization.

H7: People-Centered Management moderates the impact of Innovativeness on Project Success.

H8: People-Centered Management moderates the impact of Risk-taking on Project Success. 
H9: People-Centered Management moderates the impact of Proactiveness on Project Success.

Below Fig. 1 explains the hypotheses and research model developed on the prior discussion.

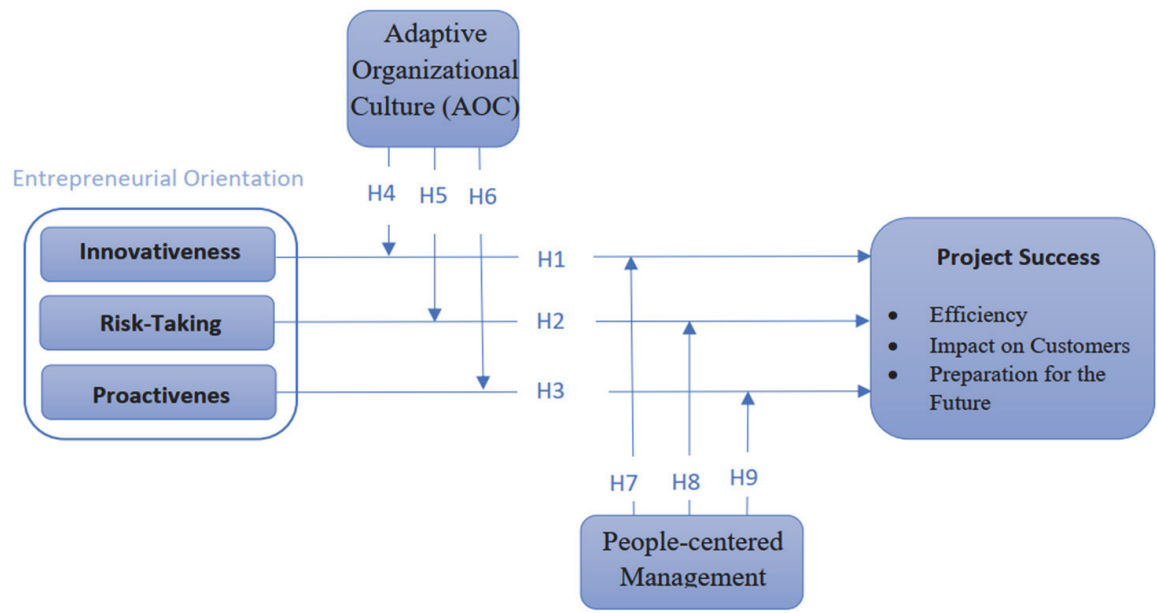

PS $=$ Project Success

$\mathrm{IN}=$ Innovativeness
Fig. 1. Conceptual Model

$\mathrm{PR}=$ Proactiveness

$\mathrm{RT}=$ Risk-Taking
AOC $=$ Adaptive Organizational Culture

$\mathrm{PCM}=$ People-Centered Management

\section{Methodology}

\subsection{Data collection process}

This research is being conducted to link entrepreneurial orientation to project success in construction projects of Punjab Pakistan. The data was collected and analyzed to answer the research questions, to achieve research objectives and to accomplish the aim of this study. The assessment of this study is based on primary data gathered from Project Managers and Team Leaders of companies related to the Construction industry through survey questionnaires and the secondary data collected by various journals, articles, conferences, and books for writing literature review and introduction. This research is quantitative in nature and completed by using homogeneous sampling through combination of convenience and judgement sampling method. This study based on questionnaire and response is collected by google forms and through telephonic interviews, questionnaire distribution, online chat rooms and emails. A total 400 questionnaires were distributed but only 256 have been returned and found appropriate for analysis. The analysis of collected data was performed by using SPSS and Smart PLS software.

\subsection{Questionnaire Development}

Questionnaire contains the questions related to Innovativeness, Risk taking, Proactiveness, Adaptive Organizational Culture, People-Centered Management and Project Success. In order to measure all the questions, a five-point Likert scale is used. This five-point Liker scale range from Strongly disagree to Strongly agree $(1=$ Strongly Disagree, $2=$ Disagree, $3=$ Neutral, $4=$ Agree, $5=$ Strongly Agree). In the questionnaire, to measure Innovativeness this study adapted 3 questions. To measure Risk-taking and Proactiveness this study adapted 3 questions for each variable. To measure Adapted Organizational Culture this study adapted 6 questions. To measure People-Centered Management this study adapted 6 questions. To measure Project Success, three further dimensions selected, and questions adapted for them as, to measure Efficiency 4 questions adapted, to measure Impact on Customer 5 questions adapted and to measure Preparation for the Future 6 questions adapted.

\subsection{Descriptive statistics}

There was a total of 256 respondents, based on this demographic majority of the respondents are male $(n=166,64.8 \%)$ whereas $35.2 \%$ of the respondents are female. Out of 256 respondents $45.3 \%$ respondents belong to the age group of $26-35$ years. In case of education level, $37.9 \%$ of the respondent have bachelor's degree, $58.2 \%$ of the respondent are from Master/MS/M.Phil. and only 3.9\% are from $\mathrm{PhD}$ group. Out of 256 respondents $53.5 \%$ of the respondents are those whose annual income is less than Rs.25,000 and only 2.3\% respondent have more than Rs.950,000 annual income. In case of Total Experience, $42.6 \%$ respondent belongs to the group having experience $5-15$ years, $37.6 \%$ of the respondent have experience less than 5 years and only $6.2 \%$ of the respondent have experience more than 25 years. 
Table 2

Respondents Demographic

\begin{tabular}{|c|c|c|c|}
\hline & & Frequency & Percentage \\
\hline \multirow{2}{*}{ Gender } & Male & 166 & 64.8 \\
\hline & Female & 90 & 35.2 \\
\hline \multirow[t]{4}{*}{ Age } & Less than 25 & 40 & 15.6 \\
\hline & $26-35$ & 116 & 45.3 \\
\hline & $36-45$ & 78 & 30.5 \\
\hline & More than 45 years & 22 & 8.6 \\
\hline \multirow[t]{4}{*}{ Marital Status } & Divorced & 11 & 4.3 \\
\hline & Married & 167 & 65.2 \\
\hline & Single & 75 & 29.3 \\
\hline & Widow & 3 & 1.2 \\
\hline \multirow[t]{3}{*}{ Education } & Bachelor s & 97 & 37.9 \\
\hline & Masters/MS/M.Phil. & 149 & 58.2 \\
\hline & $\mathrm{PhD}$ & 10 & 3.9 \\
\hline \multirow[t]{4}{*}{ Annual Income } & Less than 350,000 & 137 & 53.5 \\
\hline & $350,000-600,000$ & 26 & 10.1 \\
\hline & $600,000-950,000$ & 87 & 34.1 \\
\hline & Above 950,000 & 6 & 2.3 \\
\hline \multirow[t]{4}{*}{ Total Experience } & Less than 5 & 94 & 36.7 \\
\hline & $5-15$ & 109 & 42.6 \\
\hline & $16-25$ & 37 & 14.5 \\
\hline & More than 25 & 16 & 6.2 \\
\hline
\end{tabular}

\section{Results}

The proposed hypotheses shown in the conceptual model have been endorsed by using Partial Least Square (PLS). SmartPLS (Partial Least Square version 3) v.3 and SPSS v.26 (Statistical Social Science System version 26) were used for the study. SEM (Structural Equation Modeling) has been used to check Smart-PLS study theories while SPSS has been used to implement population research and to establish relationships between variables. SEM is a technique used specifically in the social sciences to perform the data analysis (Leguina, 2015). SEM is commonly used for the determination of the relationship between multiple variables. This is commonly used in the social sciences since it is used continuously to check several variables to interpret the results. SEM assists in assessing the interdependencies between the different variables.

\subsection{Reliability and Validity Analysis}

Table 3 displayed the Cronbach Alpha value of this aggregated survey. Reliability of all the variables is studied to check their internal consistency with Cronbach's alpha value that should be greater than 0.7 . In this study, the Cronbach alpha of all the variables lie above this value with a minimum value of 0.719 corresponding to the independent variable IN. Composite reliability is also used to show the internal consistency of the constructs. It's value for reliability should lie between 0.70 and 0.90 to be acceptable. A value greater than 0.95 shows that the variable is showing the same phenomenon. In this research the values of all the constructs are in the normal ranges of Cronbach's Alpha and Composite Reliability which means that the measures of our variables are reliable, as shown in the table below. Table 3 also shows the Average Value Extracted (AVE), which shows the validity of the construct and to check the level to which the items are explaining the variables. The cut off value for this study is 0.5 , the items should have value greater than this. In this research, the values of items IN_3, AOC_3, PSEF_1, PSEF_5, PSIC_3, PSPF_1 and PSPF_4 were removed to attain the result with reliability values above 0.5 . AVE gives the validity of the constructs showing that all the items of that construct are measuring the construct.

Table 3

Construct reliability and validity

\begin{tabular}{|c|c|c|c|c|}
\hline & Cronbach's & & Composite & Average Variance \\
\hline & Alpha & & Reliability & Extracted (AVE) \\
\hline IN & 0.719 & 0.762 & 0.874 & 0.777 \\
\hline PR & 0.774 & 0.779 & 0.869 & 0.689 \\
\hline RT & 0.745 & 0.772 & 0.851 & 0.655 \\
\hline PCM & 0.830 & 0.85 & 0.874 & 0.537 \\
\hline PS & 0.903 & 0.907 & 0.920 & 0.536 \\
\hline AOC & 0.790 & 0.834 & 0.851 & 0.535 \\
\hline
\end{tabular}

\subsection{Discriminant Validity}

Discriminant validity is described as a condition when more than two independently various ideas are not related/correlated to each other (Lambert \& Larcker, 1987). Discriminant validity is displayed in Table 4 and 5 by the Fornell-Larcker criterion and Heterotrait-Monotrait Ratio (HTMT), respectively. The discriminant validity was analyzed to check the level of how much a construct differs from the other. In discriminant validity the square root of AVE is taken to check if it is greater than the correlation of the variables or not. If this discriminant validity is greater than the correlations, then the data is assumed to 
have discriminant validity. The table inserted below shows the discriminant validity in which the values at the top of the diagonals should be greater than the underlying values of each column. The AVE square root as presented in Table 4, is larger than the correlation of the inter construct. The findings of the analyses show that the bold green values are higher than the correlation among the construct and other construct match with the rows and columns which indicate that there is no issue with discriminant validity.

Table 4

Fornell-Larcker criterion

\begin{tabular}{llllll}
\hline & AOC & IN & PCM & PR & PS \\
\hline AOC & $\mathbf{0 . 7 3 2}$ & & & & \\
IN & 0.188 & $\mathbf{0 . 8 8 1}$ & & & \\
PCM & 0.652 & 0.236 & $\mathbf{0 . 7 3 2}$ & $\mathbf{0 . 8 3}$ & \\
PR & 0.453 & 0.323 & 0.538 & 0.662 & $\mathbf{0 . 7 3 2}$ \\
PS & 0.575 & 0.343 & 0.695 & 0.519 & 0.53 \\
RT & 0.432 & 0.383 & 0.493 & $\mathbf{0 . 8 1}$ \\
\hline
\end{tabular}

\subsection{Heterotrait-Monotrait Ratio (HTMT)}

The value of Heterotrait-Monotrait Ratio (HTMT) should be less than 0.9 (Edmans \& Holderness, 2017). Table 5 shows that HTMT 0.850 is the highest HTMT correlation ratio which establishes an adequate level of discriminant validity which shows an acceptable level of measurement model.

Table 5

Heterotrait-Monotrait Ratio (HTMT)

\begin{tabular}{|c|c|c|c|c|c|c|}
\hline & AOC & IN & PCM & PR & PS & RT \\
\hline \multicolumn{7}{|l|}{$\overline{\mathrm{AOC}}$} \\
\hline IN & 0.242 & & & & & \\
\hline РСМ & 0.850 & 0.271 & & & & \\
\hline PR & 0.590 & 0.436 & 0.659 & & & \\
\hline PS & 0.627 & 0.417 & 0.734 & 0.785 & & \\
\hline RT & 0.554 & 0.505 & 0.618 & 0.656 & 0.618 & \\
\hline
\end{tabular}

\subsection{Correlation}

During the analysis, the correlation between the variables was found to be positive with moderate to strong relation. A correlation is considered significant if the values of correlation fall in the range of -1.000 to +1.000 , whereas the type of correlation is determined by their magnitude. If the values lie close to +1.000 or -1.000 then the correlation is considered strong and if close to zero, they are considered weak. According to the analysis in the table 6 listed below, correlation between IN \& RT is 0.649 showing a moderately positive relationship. However, correlation between RT \& PS is 0.956 which shows a very strongly positive relationship. The correlation between PR \& AOC is 0.085 which is a very weakly positive relationship. The table given below shows the correlation between all the independent, dependent, and moderating variables.

Table 6

The results of Correlation ratios

\begin{tabular}{|c|c|c|c|c|c|c|c|}
\hline & & Innovativeness & Risk Taking & Proactiveness & $\begin{array}{l}\text { Adaptive } \\
\text { Organizational } \\
\text { Culture } \\
\end{array}$ & $\begin{array}{l}\text { People } \\
\text { Centered } \\
\text { Management } \\
\end{array}$ & $\begin{array}{l}\text { Project } \\
\text { Success }\end{array}$ \\
\hline \multirow{3}{*}{ Innovativeness } & Pearson Correlation & 1 & $.649 * *$ & $.509 * *$ & $.214^{* *}$ & $.465 * *$ & $.654 * *$ \\
\hline & Sig. (2-tailed) & & 0.000 & 0.000 & 0.001 & 0.000 & 0.000 \\
\hline & $\mathrm{N}$ & 256 & 256 & 256 & 256 & 256 & 256 \\
\hline \multirow{3}{*}{ Risk Taking } & Pearson Correlation & $.649 * *$ & 1 & $.741 * *$ & $.177 * *$ & $.873 * *$ & $.956^{* *}$ \\
\hline & Sig. (2-tailed) & 0.000 & & 0.000 & 0.004 & 0.000 & 0.000 \\
\hline & $\mathrm{N}$ & 256 & 256 & 256 & 256 & 256 & 256 \\
\hline \multirow{3}{*}{ Proactiveness } & Pearson Correlation & $.509 * *$ & $.741 * *$ & 1 & 0.085 & $.681 * *$ & $.793 * *$ \\
\hline & Sig. (2-tailed) & 0.000 & 0.000 & & 0.000 & 0.000 & 0.000 \\
\hline & $\mathrm{N}$ & 256 & 256 & 256 & 256 & 256 & 256 \\
\hline \multirow{3}{*}{$\begin{array}{l}\text { Adaptive Organ- } \\
\text { izational Culture }\end{array}$} & Pearson Correlation & $.214 * *$ & $.177 * *$ & 0.085 & 1 & $.139 *$ & $.172 * *$ \\
\hline & Sig. (2-tailed) & 0.001 & 0.004 & 0.175 & & 0.026 & 0.006 \\
\hline & $\mathrm{N}$ & 256 & 256 & 256 & 256 & 256 & 256 \\
\hline \multirow{3}{*}{$\begin{array}{l}\text { People Centered } \\
\text { Management }\end{array}$} & Pearson-Correlation & $.465 * *$ & $.873^{* *}$ & $.681 * *$ & $.139^{*}$ & 1 & $.912 * *$ \\
\hline & Sig. (2-tailed) & 0.000 & 0.000 & 0.000 & 0.026 & & 0.000 \\
\hline & $\mathrm{N}$ & 256 & 256 & 256 & 256 & 256 & 256 \\
\hline \multirow{3}{*}{ Project Success } & Pearson Correlation & $.654 * *$ & $.956^{* *}$ & $.793 * *$ & $.172 * *$ & $.912 * *$ & 1 \\
\hline & Sig. (2-tailed) & 0.000 & 0.000 & 0.000 & 0.006 & 0.000 & \\
\hline & $\mathrm{N}$ & 256 & 256 & 256 & 256 & 256 & 256 \\
\hline
\end{tabular}

**. Correlation is significant at the 0.01 level (2-tailed)

*. Correlation is significant at the 0.05 level (2-tailed) 


\subsection{Hypotheses testing}

The analysis was done in Smart PLS 3 and the model that was used is made on the basis of the conceptual framework of the study. In this model, three independent latent variables are constructed on the left. In the center are the moderating variables of the study and the last variable PS is the dependent variable of the research model. All the variables in the model are depicted with their respective items. Although the moderating variables are visible, their moderation has not yet been applied. The moderation was also applied in the bootstrap analysis. In Smart PLS, the bootstrapping uses randomly drawn observations to create subsamples from the original data. In this research, 2000 samples were generated through bootstrapping to figure out the path coefficients of the thesis hypotheses. In Table 7, the results generated by the bootstrapping shows the direction and the magnitude of the variables and the prevailing relationship between them. Greater path coefficient values mean a stronger relationship between dependent and independent variables. The P-value indicating a value lower than 0.05 means significant relationship which also corresponds to a greater T-value of more than 1.96. In this research data that shows 9 hypotheses, 7 had significant results whereas, 2 hypotheses were insignificant due to their P-values being more than 0.05 and T-values less than 1.96 .

Table 7

The results of path coefficients

\begin{tabular}{|c|c|c|c|c|c|}
\hline & Original & Standard & T Statistics & \multirow{3}{*}{ _P Values } & \multirow[t]{3}{*}{ Hypothesis } \\
\hline & Sample & Deviation & $(|\mathrm{O} / \mathrm{STDEV}|)$ & & \\
\hline & $(\mathrm{O})$ & (STDEV) & & & \\
\hline $\mathrm{IN} \rightarrow \mathrm{PS}$ & 0.061 & 0.023 & 2.698 & 0.004 & Supported \\
\hline $\mathrm{RT} \rightarrow \mathrm{PS}$ & 0.406 & 0.040 & 10.021 & 0.000 & Supported \\
\hline $\mathrm{PR} \rightarrow \mathrm{PS}$ & 0.308 & 0.032 & 9.547 & 0.000 & Supported \\
\hline $\mathrm{IN}-\mathrm{AOC} \rightarrow \mathrm{PS}$ & 0.184 & 0.108 & 1.965 & 0.045 & Supported \\
\hline $\mathrm{RT}-\mathrm{AOC} \rightarrow \mathrm{PS}$ & 0.246 & 0.176 & 1.402 & 0.081 & Un-Supported \\
\hline $\mathrm{PR}-\mathrm{AOC} \rightarrow \mathrm{PS}$ & -0.184 & 0.114 & 1.617 & 0.053 & Un-Supported \\
\hline IN-PCM $\rightarrow$ PS & 0.053 & 0.029 & 2.372 & 0.036 & Supported \\
\hline RT-PCM $\rightarrow$ PS & 0.188 & 0.056 & 3.362 & 0.000 & Supported \\
\hline PR-PCM $\rightarrow$ PS & 0.078 & 0.048 & 1.987 & 0.049 & Supported \\
\hline
\end{tabular}

In this model we have used two moderating variables AOC and PCM. Both these variables are moderating the effects of all the independent variables (IN, RT, PR) on dependent variable PS. In this moderation, the effect of the responses from each item of each independent variable was multiplied with the dependent variable. The results of the bootstrapping algorithm when applied to the model are listed as path coefficients in the table listed below. Moderation of AOC on PR and RT is nonsignificant.

\subsection{Coefficient of Determination $\left(R^{2}\right)$}

The coefficient of determination $\left(\mathrm{R}^{2}\right)$ is the value that shows the relationship between dependent and independent variables. Inspected value of R-square is given in table 8. It gives an understanding of this relationship either it is strong, weak, or moderate (Henseler et al., 2015), (Henseler et al., 2016). $\mathrm{R}^{2}$ gives the percentage value of how much relationship exists between the dependent and independent variables. 75\% relation means strong relationship, $25 \%$ relation means weak relationship and around 50\% means moderate relationship. Analysis of this research shows a $\mathrm{R}^{2}$ value of 0.626 which means that the independent variables are $62.6 \%$ related to the dependent variable PS. In table 8 adjusted R-square value is 0.619 which shows the project success is (dependent Variable) get affected by Innovativeness, Risk taking, Proactiveness with moderating role of Adaptive Organizational Culture and People-Centered Management by $61.9 \%$. This shows that there is a strong association between variables.

Table 8

The results of R-Square

\begin{tabular}{ccc}
\hline & R-Square & R-Square Adjusted \\
PS & 0.626 & 0.619 \\
\hline
\end{tabular}

\section{Discussion}

\subsection{Conclusion}

The main aim of this study is to find out the link between Entrepreneurial Orientation and project success in the construction Industry. This study analyzes the association among various variables such as Innovativeness, Risk Taking, Proactiveness, Adaptive Organizational Culture, People Centered Management and Project success. This research is conducted in the Construction industry of Punjab Pakistan, Pakistan and provides us the basis to realize the linking between Entrepreneurial Orientation on Project Success. These observable variables have been measured with their respective survey items and found 
positively correlated with the independent variable of Entrepreneurial Orientation. This research is conducted by using homogeneous sampling through combination of convenience and judgement sampling method. A structure equation modeling by partial least square is used to check the relation of Entrepreneurial Orientation with project success. To test the internal consistency of model CR and Cronbach's Alpha value is used. The results of Cronbach's Alpha depict consistency among individual items of the construct and participants and it also indicates that the survey results have significant reliability. Based on the findings of the measurement model, it is clear that the model has discriminant validity.

The results of this research study show that the independent variables of the entrepreneurial orientation explain $62.6 \%$ of the project-success. These results show a positive and significant relationship of the entrepreneurial orientation over projectsuccess. In the results, this relationship is significantly proven. All the three variables of the entrepreneurial orientation have a significant and positive relation with the project-success as shown in the results of $\mathrm{H} 1, \mathrm{H} 1$ and $\mathrm{H} 3$. In all these hypotheses tests of direct relations, the t-value were more than 1.96 and the p-values were less than 0.05 . These results from the analysis confirms the already established relationship between dependent and independent variables of the research from the literature review. These results also indicate that the success of the project can be increased if organizations that are working on projects implement the entrepreneurial orientation with innovation, proactiveness and risk taking.

With the moderation of adaptive organizational culture (H4, H5, H6), we can see that hypotheses H5 and H6 are non-significant and hence can be rejected where as $\mathrm{H} 4$ is accepted. H4 indicates that adaptive organizational culture positively moderates the impact of Innovativeness on project-success. Whereas adaptive organizational culture does not moderate the impact of proactiveness and risk-taking on project-success. The moderation of people-centered management can be established that it positively impacts the relation of Innovativeness, proactiveness and risk-taking on project-success. The significant results of moderation of PCM indicates that the combined effect of PCM and IN shows significant results on PS. Combined effect of PCM and PR also proves significant on PS. RT when moderated with PCM gives a significant result on PS. Hence, we can say that PCM positively influences the EO on project-success.

From these analysis results it can be seen that in an organization the success of the projects can be enhanced by the induction of people-centered management and focusing the management practices characterized by entrepreneurial orientation that focuses on Innovativeness, proactiveness and risk-taking behavior. Whereas adaptive organizational culture does not play a significant role in comprehensively influencing the role of entrepreneurial orientation on project-success.

The exploration discoveries bolster the contentions found in EO writing that an association's capacity to create and keep up an AOC is driven by the association's vital stance towards business enterprise (Hitt et al., 2008). Likewise, the discoveries give exact proof supporting Kelermans and Edleston's (2006) proposal that an AOC can be incited by enterprising conduct (Dayen et al. 2016). Besides, the examination discoveries bolster the contention that PCM is a value creating instrument for associations seeking after enterprising methodologies (Ling 2013; Ros, Banbrige and Jocabson 2001). PCM that improves relational associations will encourage the age and sharing of information through communication with association individuals and outside systems, which will upgrade the association's seriousness and execution (Ling 2013). In conclusion, the discoveries bolster the contention that AOC positively affects HRM exercises, for example, PCM (Adams et al., 2016) (Ngo and Loi 2008). In this way, an EO firm that seeks after the advancement of an A-O-C and P-C-M initiative style will achieve an upper hand bringing about upgraded firm execution. Developing economies, for example, South Korea, are encountering institutional changes, which present difficulties and open doors for E-O firms endeavoring to improve their development. Rising economies are executing market-oriented arrangements as a component for animating national financial development and prod business. In this way, the modern parts in developing "economies are encountering quick basic changes, expanded condition vulnerability and uneven development" (Shirokova et al., 2016). These elements have formed the administration tasks and procedures on the best way to seek after circumstances in EO-driven firms and how worth is made for clients and the firm (Bogetyrva et al. 2017). In that capacity, firms' P-C-M and A-O-C exercises take on an expanded pertinence in such economies (Booso, Storry, and Cadoggan 2013). As to suggestions, surviving exploration features a few factors that support business enterprise. One striking element is the probability of the accomplishment of the undertaking (Gauer, Maa, and Dieng 2018; Krassniqi 2012). Consequently, policymakers can assume a job in encouraging positive conditions for 18 Y.- M. JEONG ET AL. business people to succeed, for example, improving guidelines to expand simplicity of working together; supporting money related asset securing for innovative work (Mukherjee et al. 2013); creating foundation to encourage a superior arranged society that facilitates relationship and constructs trust between associations (Gauer et al. 2011); and advancing internationalization inside the economy (Sing, Gauer, and Schmed 2010; Volchek, Henttonen, and Edelmann 2013).

\subsection{Implications}

In the research field, this thesis reveals insight into the commitment of entrepreneurial orientation to PS. Comprehensively, the thesis adds to the advancement of studies connecting business enterprise and management of projects and reinforces the bond between entrepreneurial orientation and project-success. Also, this thesis contributes to contemplating trying to comprehend the components that impact the PS, just as it adds to the advantages of EO for different firms. Mulled over the prevailing gap in the studies that connects PS to entrepreneurial orientation, this research assists with limiting it and to additionally animate exploration in this field. 
In practical fields, understanding the elements or features that can add to PS and are also able to influence the firm's growth (like AOC and PCB), could assist firms with getting upper hand. This thesis supports the hypothetical model bringing up to project managers the significance of creating in their own firms to achieve PS through the application of adaptive organizational culture and people-centered management.

Hence, the outcomes of this study recommend that project management practices can be adjusted to the firm's innovative direction (EO) along with adaptive organizational culture and people-centered management to empower firms to improve their projects and achieve an upper hand among the competitors. It also, with the extent of the effect of EO on success of the projects $(62.6 \%)$ mentioned in this research, it is important that managers with project management skill grow their viewpoint to perceive different variables (e.g. AOC, PCM) that influence the success of a project.

\subsection{Limitations}

In the limitations of this research, it is significant that the outcomes are constrained to the population of organizations conducting projects in Punjab Pakistan, Pakistan. This impediment creates an open door for later research in this field on expansion of the model for explicit fields of project segments and using other moderating or mediating variables just as AOC or PCM. Furthermore, the success criteria were measured at a specific time when the COVID-19 pandemic was prevailing when the respondents were hesitant to provide information due to physical contact. Online collection of data was found to be very difficult and showed non-serious behavior of the respondents. As the data was collected at a single instance, the respondent was asked to imagine that the project has already been completed.

\section{References}

Acs, Z. J., Estrin, S., Mickiewicz, T., \& Szerb, L. (2018). Entrepreneurship, institutional economics, and economic growth: an ecosystem perspective. Small Business Economics, 51(2), 501-514.

Klewitz, J., \& Hansen, E. G. (2014). Sustainability-oriented innovation of SMEs: a systematic review. Journal of cleaner production, $65,57-75$.

Javier Alvarez-Torres, F., Citlalli Lopez-Torres, G., \& Schiuma, G. (2019). Linking entrepreneurial orientation to SMEs' performance Implications for entrepreneurship universities. MANAGEMENT DECISION, 57(12), 3364-3386.

Anderson, B. S., Kreiser, P. M., Kuratko, D. F., Hornsby, J. S., \& Eshima, Y. (2015). Reconceptualizing entrepreneurial orientation. Strategic management journal, 36(10), 1579-1596.

Arora, S., \& Kaur, S. (2018). Perceived Risk Dimensions and its Impact on Intention to Use E-Banking Services: A Conceptual Study. Journal of Commerce and Accounting Research, 7(2), 18.

Bammens, Y., Notelaers, G., \& Van Gils, A. (2015). Implications of family business employment for employees' innovative work involvement. Family Business Review, 28(2), 123-144.

Begeç, S., \& Arun, K. (2020). The bottleneck of intrapreneurship: are social positions and held expectations constraints in organizations' entrepreneur process? A conceptual view. Journal of Entrepreneurship in Emerging Economies.

Boermans, M. A., \& Willebrands, D. (2017). Entrepreneurship, risk perception and firm performance. International Journal of Entrepreneurship and Small Business, 31(4), 557-569.

Boon, C., Eckardt, R., Lepak, D. P., \& Boselie, P. (2018). Integrating strategic human capital and strategic human resource management. The International Journal of Human Resource Management, 29(1), 34-67.

Cho, Y. H., \& Lee, J. H. (2018). Entrepreneurial orientation, entrepreneurial education and performance. Asia Pacific Journal of Innovation and Entrepreneurship.

Covin, J. G., \& Wales, W. J. (2019). Crafting high-impact entrepreneurial orientation research: Some suggested guidelines.

Do, B. R., Yeh, P. W., \& Madsen, J. (2016). Exploring the relationship among human resource flexibility, organizational innovation and adaptability culture. Chinese Management Studies.

Edmans, A., \& Holderness, C. G. (2017). Blockholders: A survey of theory and evidence. The handbook of the economics of corporate governance, 1, 541-636.

Eisend, M., Evanschitzky, H., \& Gilliland, D. I. (2016). The influence of organizational and national culture on new product performance. Journal of Product Innovation Management. https://doi.org/10.1111/jpim. 12268

Engert, S., Rauter, R., \& Baumgartner, R. J. (2016). Exploring the integration of corporate sustainability into strategic management: a literature review. Journal of cleaner production, 112, 2833-2850.

Maria, E., \& Martin, F. (2015). Risk Management in SMEs: A Systematic Review of Available Evidence.

Helfat, C. E., \& Peteraf, M. A. (2015). Managerial cognitive capabilities and the microfoundations of dynamic capabilities. Strategic management journal, 36(6), 831-850.

Henseler, J., Ringle, C. M., \& Sarstedt, M. (2015). A new criterion for assessing discriminant validity in variance-based structural equation modeling. Journal of the academy of marketing science, 43(1), 115-135.

Zaiţ, A., \& Bertea, P. S. P. E. (2011). Methods for testing discriminant validity. Management \& Marketing Journal, 9(2), $217-$ 224.

Hiebl, M. R., Duller, C., \& Neubauer, H. (2019). Enterprise risk management in family firms: evidence from Austria and Germany. The Journal of Risk Finance. 
Hitt, M. A., Ireland, R. D., Camp, S. M., \& Sexton, D. L. (2002). Strategic entrepreneurship: Integrating entrepreneurial and strategic management perspectives. Strategic entrepreneurship: Creating a new mindset, 1, 16.

Hong, J. C., Lin, P. H., \& Hsieh, P. C. (2017). The effect of consumer innovativeness on perceived value and continuance intention to use smartwatch. Computers in Human Behavior, 67, 264-272.

Jirásek, M., \& Bílek, J. (2018). The organizational life cycle: Review and future agenda. Quality Innovation Prosperity, 22(3), 01-18.

Kantur, D. (2016). Strategic entrepreneurship: mediating the entrepreneurial orientation-performance link. Management Decision.

Kim, D. H., Yu, G. J., \& Lee, K. C. (2018). A Study on the Relationship Between Entrepreneurial Orientation and Company Performance in Entertainment Firms. The Journal of the Korea Contents Association, 18(2), 11-25.

Lambert, R. A., \& Larcker, D. F. (1987). An analysis of the use of accounting and market measures of performance in executive compensation contracts. Journal of Accounting research, 85-125.

Le Roux, C., \& Pretorius, M. (2016). Navigating sustainability embeddedness in management decisionmaking. Sustainability, 8(5), 444.

Hair Jr, J. F., Hult, G. T. M., Ringle, C., \& Sarstedt, M. (2016). A primer on partial least squares structural equation modeling (PLS-SEM). Sage publications.

Lim, E., \& Kim, D. (2019). Entrepreneurial Orientation and Performance in South Korea: The Mediating Roles of Dynamic Capabilities and Corporate Entrepreneurship. Entrepreneurship Research Journal, 1(ahead-of-print).

Bandeira-De-Mello, R. (2006). Softwares em pesquisa qualitativa. Pesquisa qualitativa em estudos organizacionais: paradigmas, estratégias e métodos. São Paulo: Saraiva, 481, 241-266.

Martin, S. L., \& Javalgi, R. R. G. (2016). Entrepreneurial orientation, marketing capabilities and performance: the moderating role of competitive intensity on Latin American International new ventures. Journal of Business Research, 69(6), 20402051.

Miller, D. (2011). Miller (1983) revisited: A reflection on EO research and some suggestions for the future. Entrepreneurship theory and practice, 35(5), 873-894.

Obschonka, M., Hakkarainen, K., Lonka, K., \& Salmela-Aro, K. (2017). Entrepreneurship as a twenty-first century skill: entrepreneurial alertness and intention in the transition to adulthood. Small Business Economics, 48(3), 487-501.

Onwe, C. C., Ogbo, A., \& Ameh, A. A. (2020). Entrepreneurial orientation and small firm performance: The moderating role of environmental hostility. Entrepreneurial Business and Economics Review, 8(4), 67-84.

Saridakis, G., Lai, Y., \& Cooper, C. L. (2017). Exploring the relationship between HRM and firm performance: A metaanalysis of longitudinal studies. Human resource management review, 27(1), 87-96.

Shirokova, G., Bogatyreva, K., Beliaeva, T., \& Puffer, S. (2016). Entrepreneurial orientation and firm performance in different environmental settings: contingency and configurational approaches. Journal of Small Business and Enterprise Development.

Hussein, B. A., Ahmad, S. B., \& Zidane, Y. J. (2015). Problems associated with defining project success. Procedia Computer Science, 64, 940-947.

Wiklund, J., \& Shepherd, D. (2003). Knowledge-based resources, entrepreneurial orientation, and the performance of small and medium-sized businesses. Strategic management journal, 24(13), 1307-1314.

Zaato, S. G., Ismail, M., Uthamaputhran, S., \& Owusu-Ansah, W. (2020). The Impact of Entrepreneurial Orientation on SMEs Performance in Ghana: The Role of Social Capital and Government Support Policies. Jurnal Manajemen dan Kewirausahaan (Journal of Management and Entrepreneurship), 22(2), 99-114. 


\section{Appendix}

\section{Table A1}

Questionnaire Items

\begin{tabular}{|c|c|c|}
\hline Constructs & Items & Adapted From \\
\hline IN- Innovativeness & $\begin{array}{l}\text { IN_1 In general, the top managers of my firm favor a strong emphasis on R\&D, technological } \\
\text { leadership and innovations. } \\
\text { IN_2 My firm marked very many new lines of products or services in the past } 5 \text { years. } \\
\text { IN_3 Changes in products or services in my firm have usually been quite dramatic in the past } 5 \\
\text { years. }\end{array}$ & $\begin{array}{l}\text { Covin and Slevin } \\
\text { (1989) }\end{array}$ \\
\hline RT - Risk-taking & $\begin{array}{l}\text { RT_1 In general, the top managers of my firm have a strong proclivity for high-risk projects (with } \\
\text { chance of very high return) } \\
\text { RT_2 In general, the top managers of my firm believe that owing to the nature of the } \\
\text { environment, bold, wide-ranging acts are necessary to achieve the firm's objectives. } \\
\text { RT_3 When confronted with decision making situations involving uncertainty, my firm typically } \\
\text { adopts a bold, aggressive posture in order to maximize the probability of exploiting potential } \\
\text { opportunities }\end{array}$ & Covin and Slevin (1989 \\
\hline PR- Proactiveness & $\begin{array}{l}\text { PR_1 In dealing with its competitors, my firm typically initiates actions which competitors then } \\
\text { respond to. } \\
\text { PR_2 In dealing with its competitors, my firm is very often the first business to introduce new } \\
\text { product/services, administrative techniques, operating technologies, etc. } \\
\text { PR_3 In general, the top managers of my firm have a strong tendency to be ahead of other } \\
\text { competitors in introducing novel ideas or products. }\end{array}$ & $\begin{array}{l}\text { Covin and Slevin } \\
\text { (1989) Lumpkin et al. } \\
(2009)\end{array}$ \\
\hline $\begin{array}{l}\text { AOC - Adaptive } \\
\text { Organizational } \\
\text { Culture }\end{array}$ & $\begin{array}{l}\text { AOC_1 The organization proactively works to identify internal and external problems; the } \\
\text { organization is able to anticipate future problems or environment changes. } \\
\text { AOC_2 The organization believes that it has the ability to change. } \\
\text { AOC_3 The organization develops the capacity to handle environmental situations. } \\
\text { AOC_4 The organization enables collaboration between business units that allow it to proactively } \\
\text { and reactively develop solutions to problems. } \\
\text { AOC_5 The organization is able to implement adaptive change. } \\
\text { AOC_6 The organization is able to sustain the change by creating systems that reinforce the } \\
\text { change. }\end{array}$ & \\
\hline $\begin{array}{l}\text { PCM - People } \\
\text { centered } \\
\text { Management }\end{array}$ & $\begin{array}{l}\text { PCM_1 In this organization people are rewarded in proportion to the excellence of their job } \\
\text { performance } \\
\text { PCM_2 We have a promotion system here that helps the best person to rise to the top } \\
\text { PCM_3 This organization is characterized by a relaxed, easygoing working climate } \\
\text { PCM_4 There is a lot of warmth in the relationships between management and workers in this } \\
\text { organization } \\
\text { PCM_5 The philosophy of our management emphasizes the human factor, how people feel, etc. } \\
\text { PCM_6 You don't get much sympathy form higher-ups in this organization if you make a } \\
\text { mistake. }\end{array}$ & \\
\hline \multicolumn{3}{|l|}{ Project Success: } \\
\hline EF - Efficiency & $\begin{array}{l}\text { PSEF_1 The project was completed on time or earlier. } \\
\text { PSEF_2 The project was completed within or below budget. } \\
\text { PSEF_3 The project had only minor changes. } \\
\text { PSEF 4 Other efficiency measures were achieved. }\end{array}$ & \\
\hline $\begin{array}{l}\text { IC- Impact on } \\
\text { Customer }\end{array}$ & $\begin{array}{l}\text { PSIC_1 The product improved the customer's performance. } \\
\text { PSIC_2 The customer was satisfied. } \\
\text { PSIC_3 The product met the customer's requirements. } \\
\text { PSIC_4 The customer is using the product. } \\
\text { PSIC_5 The customer will come back for future work. }\end{array}$ & \\
\hline $\begin{array}{l}\mathrm{PF} \text { - Preparation for } \\
\text { the Future }\end{array}$ & $\begin{array}{l}\text { PSPF_1 The project outcome will contribute to future projects. } \\
\text { PSPF_2 The project will lead to additional new products. } \\
\text { PSPF_3 The project will help create new markets. } \\
\text { PSPF_4 The project created new technologies for future use. } \\
\text { PSPF_5 The project contributed to new business processes. } \\
\text { PSPF_6 The project developed better managerial capabilities }\end{array}$ & $\begin{array}{l}\text { Shenhar and Dvir } \\
(2007)\end{array}$ \\
\hline
\end{tabular}


(C) 2020 by the authors; licensee Growing Science, Canada. This is an open access article distributed under the terms and conditions of the Creative Commons Attribution (CC-BY) license (http://creativecommons.org/licenses/by/4.0/). 